\title{
Chemically synthesized one-dimensional zinc oxide nanorods for ethanol sensing
}

\author{
M. Z. Ahmad ${ }^{1}$, A. Z. Sadek', K. Latham ${ }^{2}$, J. Kita ${ }^{3}$, R. Moos ${ }^{3}$ and W. Wlodarski ${ }^{1}$ \\ ${ }^{1}$ School of Electrical and Computer Engineering, RMIT University, Melbourne, Australia \\ ${ }^{2}$ School of Applied Sciences, RMIT University, Melbourne, Australia \\ ${ }^{3}$ Department of Functional Materials, University of Bayreuth, Bayreuth, Germany \\ Corresponding author e-mail: zamharir@gmail.com
}

\begin{abstract}
One-dimensional (1D) zinc oxide ( $\mathrm{nnO}$ ) nanorod (NR) based conductometric sensors have been developed and investigated towards ethanol vapor. The ZnO NRs were chemically synthesized onto alumina substrates with patterned interdigitated transducers (IDT) using a hydrothermal method. A seed layer of $\mathrm{ZnO}$ nanoparticles was pre-deposited onto the transducer substrates using a filtered cathodic vacuum arc (FCVA) technique. This seed layer was employed for the subsequent growth of NRs. Micro-characterization studies revealed that the grown $\mathrm{ZnO}$ has a rod like feature with an average diameter of $30-50 \mathrm{~nm}$ and an average length of $1.2 \mu \mathrm{m}$. The X-ray diffraction (XRD) analysis revealed that both $\mathrm{ZnO}$ seed layer and the NRs have a single crystal $1 \mathrm{D}$ nanostructure. The sensor performance was evaluated for ethanol vapor at operating temperatures from room to $330^{\circ} \mathrm{C}$. The study showed that the optimum operating temperature is in the range of 280 to $310^{\circ} \mathrm{C}$. At this temperature range, enhanced sensitivity, fast response and recovery with stable baseline were observed.
\end{abstract}

Key words: Ethanol sensors, $\mathrm{ZnO}$ nanorods, one-dimensional nanostructures, filtered cathodic vacuum arc

\section{Introduction}

Semiconducting metal-oxides in the form of nanobelts, nanorods, nanoribbons and nanowires are of growing importance for the development of highly sensitive gas sensors. They offer higher surface-to-volume ratios than the conventional polycrystalline structures. It is well known that the sensitivity of solid state gas sensors increases with smaller grain size [1], as this increases the effective surface area of the sensitive layer to interact with the gas molecules.

Among the semiconducting metal oxides, $\mathrm{ZnO}$ is unique because it exhibits dual semiconducting and piezoelectric properties which make them suitable for a range of device applications [2-4]. Low dimensional ZnO NRs, with a distinct structural morphology are very promising for the development of gas sensors [5]. Their large exposed surface area and complete depletion of carriers inside the rod increases the intensity of reactions. Most literature reports [1] on ZnO NRs gas sensors indicate that significant gas sensing performance improvement has been achieved. However, until now most of the reported $\mathrm{ZnO}$ nanostructures have polycrystalline structures which reduces the sensor performance [6]. In this paper, one-dimensional $\mathrm{ZnO}$ NRs were chemically grown using a FCVA deposited $\mathrm{ZnO}$ seed layer in a hydrothermal bath and investigated towards ethanol vapour.

Ethanol $\left(\mathrm{C}_{2} \mathrm{H}_{5} \mathrm{OH}\right)$ is highly flammable both as vapour and liquid. During the past years, this organic compound has gained enormous attention from researchers and has been utilized for a wide range of applications in industry [7, 8]. Some of the ethanol applications in the industry are feedstock for various products such as disinfectant, solvent to food components and alternative fuel [7-9]. Thus, there is a need for the development of sensitive, selective, robust and inexpensive ethanol sensors to monitor industrial processes. Hydrothermal synthesis employing seed-layer as the nanostructure facilitator has been a popular low cost technique to form $\mathrm{ZnO}$ nanostructures [9]. However, $\mathrm{ZnO}$ NRs grown from a FCVA deposited seed layer followed by hydrothermal synthesis have not yet been reported in literature. Other $\mathrm{ZnO}$ seed layers reported were deposited employing if sputtering and spray pyrolysis techniques $[5,10,11]$. In FCVA, the deposited ion energy 
can be controlled using the substrate bias voltage and hence a wide variety of film morphologies can be achieved. In this work, by optimizing ion energy, deposition temperature and background gas pressure, we achieved 1D $\mathrm{ZnO}$ nanoparticle seed layer.

\section{Experimental}

An FCVA deposition technique was employed to deposit a layer of $\mathrm{ZnO}$ onto alumina substrates with patterned gold IDTs. The cleaned substrates were placed on a metallic plate holder supported on a variable temperature heater. Once the deposition is completed, the substrate was taken out from the chamber and examined. The transparent $\mathrm{ZnO}$ seed layer will serve as a nucleation site for the subsequent synthesis of $\mathrm{ZnO}$ NRs employing hydrothermal method. To grow $\mathrm{ZnO}$ NRs on the substrates, an equimolar aqueous solution of zinc nitrate hexahydrate $\left(\mathrm{Zn}\left(\mathrm{NO}_{3}\right)_{2} \cdot 6 \mathrm{H}_{2} \mathrm{O}\right)$ and hexamethylenetetramine or HMT $\left(\mathrm{C}_{6} \mathrm{H}_{12} \mathrm{~N}_{4}\right)$, purchased from Sigma Aldrich, Australia were prepared and diluted in $200 \mathrm{ml}$ of de-ionized water as the standard precursor solution. The transducers were cleaned in ultrasonic bath with acetone then ethanol, and dried with nitrogen $\left(\mathrm{N}_{2}\right)$ at room temperature. The transducer was placed inverted on a custom made Teflon holder to avoid having any unwanted precipitates and was attached to a glass rod before securely inserted into the reaction bottle (Fig. 1). The reaction bottle is transferred into a laboratory grade oven with growth temperature and duration time set to $80{ }^{\circ} \mathrm{C}$ and 16 hours, respectively. Once the process is complete, the substrate was then taken out of the reaction bottle and thoroughly washed with deionized water to remove any residual zinc salts and dried in a stream of $\mathrm{N}_{2}$ at a constant flow of $200 \mathrm{sccm}$ prior to microstructural and electrical characterization.

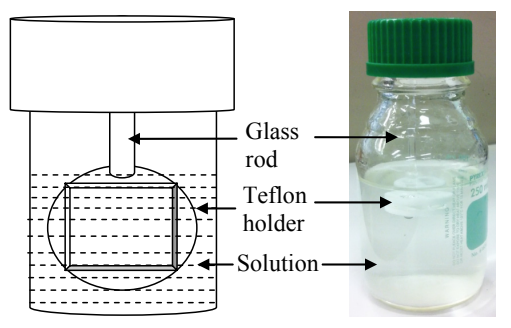

Fig. 1: Schematic diagram and camera image of reaction bottle used for ZnO NRs growth.

Films thickness was measured using a Tencor P-16 Profilometer. Scanning electron microscopy (SEM) was performed using a FEI Nova NanoSEM. X-ray diffraction (XRD) was carried out using a Bruker D8 Discover micro- diffractometer fitted with a GADDS (General Area Detector Diffraction System). A potential of $40 \mathrm{kV}$ and a current of $40 \mathrm{~mA}$ were applied during the XRD-measurement and it was filtered with a graphite monochromator in the parallel mode (175 mm collimator with $0.5 \mathrm{~mm}$ pinholes). Data was collected at room temperature using $\mathrm{Cu} \mathrm{Ka}$ radiation $(\lambda=1.54178 \AA)$.

For electrical characterization, the gold electrodes on the substrate were attached to gold wires using a mixture of silver epoxy and resin of a 1:1 consistency ratio. Once silver epoxy is cured, the sensor was then mounted in a gas chamber which was placed in an environmental enclosure. The chamber was connected to a computerized multi-channel gas calibration system using mass flow controllers (MFCs). The MFCs were used to control the ethanol concentration balanced in synthetic air. A heater was placed beneath the sensor and a DC power supply was connected to the heater to vary the operating temperature. The synthetic air was used as a carrier gas and used to dilute the concentration of the ethanol vapour. The process starts with a flow of synthetic air into the gas chamber. After the sensor reached a saturation level in synthetic air, the synthetic air flow was stopped and an ethanol concentration of 250 ppm was purged into the chamber. The approximate time for the sensor to reach saturation point after ethanol vapour exposure is $240 \mathrm{~s}$. Once the saturation point was reached, ethanol flow was stopped and synthetic air was purged into the chamber again. The process was repeated for every $20{ }^{\circ} \mathrm{C}$ interval ranging from room temperature to $330{ }^{\circ} \mathrm{C}$.

\section{Results and discussion}

\section{Micro-characterization results:}

Film thickness of the deposited $\mathrm{ZnO}$ seed layer was measured to be $20 \mathrm{~nm}$ (approx.). The SEM image in Fig. 2 revealed a highly uniform growth of $\mathrm{ZnO}$ nanostructures.

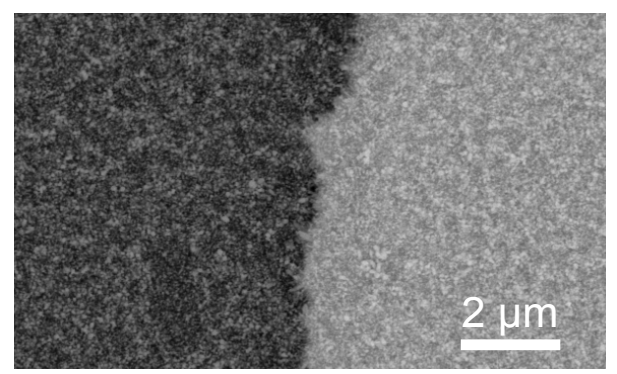

Fig. 2: SEM image showing the growth of $\mathrm{ZnO}$ nanostructures on both alumina (dark) and gold (bright). 
The image shows the $\mathrm{ZnO}$ nanostructures grown (low magnification) on top of the substrate surface shows uniformly distributed NRs covering the surface including IDT (bright) and the substrate (dark). At a higher magnification (Fig. 3), the SEM image revealed that the grown $\mathrm{ZnO}$ nanostructures on alumina substrate are consisting of highly dense, uniform NRs. The average diameter of $\mathrm{ZnO}$ NRs are around $30-50 \mathrm{~nm}$.

The $\mathrm{ZnO}$ NRs on the gold IDTs and the alumina surfaces were also examined for further analysis. It was observed that the density and morphology of the NRs varies depending on the substrate types. NRs are densely pact on gold IDTs (Fig. 3 (left)) and are not fully vertical to the substrate. NRs on the alumina are vertically aligned to the substrate and they are less dense compared to the NRs on gold IDTs.

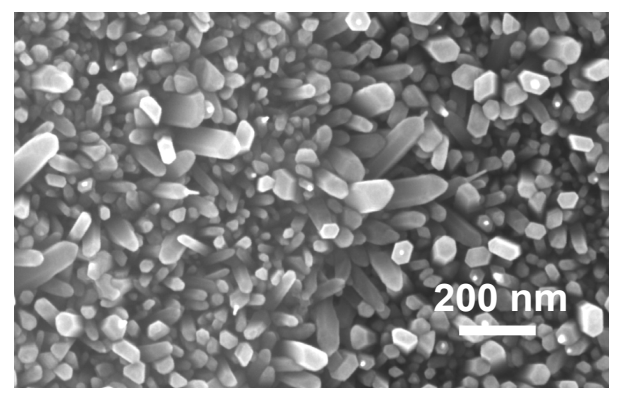

Fig. 3: SEM image of ZnO NRs on gold IDT (left) and alumina substrate (right).

XRD analysis was performed to examine the chemical composition and crystalline phase of the $\mathrm{ZnO}$ thin films (both seed layer and NRs) deposited on the substrate. XRD patterns of $\mathrm{ZnO}$ seed layer, $\mathrm{ZnO} \mathrm{NRs}$, and $\mathrm{ZnO} \mathrm{NRs}$ annealed at $300{ }^{\circ} \mathrm{C}$ (Fig. 4) confirm the single-phase, crystalline, highlyoriented nature of all three film types, with a single reflection at $\sim 34.5^{\circ} 2 \theta$ corresponding to diffraction from the (002) lattice plane of wurtzite $\mathrm{ZnO}$ (ICDD 36-1451).

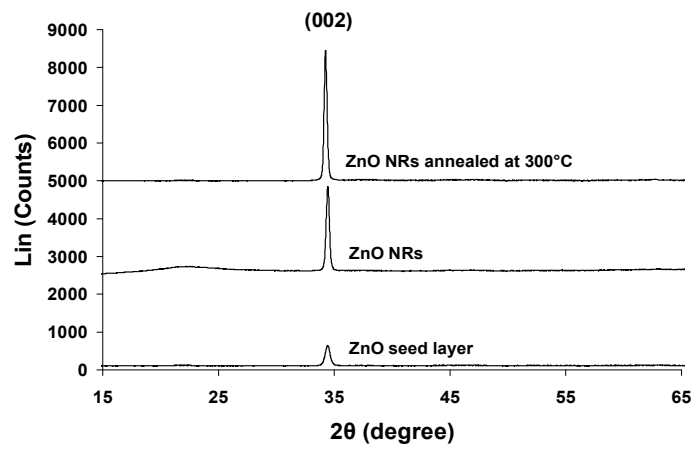

Fig. 4: XRD spectrum of $\mathrm{ZnO}$ seed layer and NRs.

\section{Electrical characterization results:}

Dynamic response of the $\mathrm{ZnO}$ NR based sensor towards ethanol with different concentrations at $280{ }^{\circ} \mathrm{C}$ is shown in Fig. 5 . The sensor response $(S)$ toward ethanol was calculated according to the equation, $S=R_{\text {air }} / R_{\text {gas }}$, where $R_{\text {air }}$ and $R_{\text {gas }}$ are sensor resistance in air and ethanol, respectively. The measured response time and recovery time towards $250 \mathrm{ppm}$ of ethanol at $280{ }^{\circ} \mathrm{C}$ is 16 and $120 \mathrm{~s}$, respectively.

The measured sensor response depending on the operating temperature is plotted in Fig. 6. It was observed that the optimum sensor operating temperature is in the range of $280-310{ }^{\circ} \mathrm{C}$. At this temperature range, the average response was calculated to be $\sim 2.26$.

The results indicate that the developed $\mathrm{ZnO}$ NR based sensor operates at a lower optimum temperature with higher sensitivity than the other polycrystalline forms of $\mathrm{ZnO}$ based ethanol sensors [12].

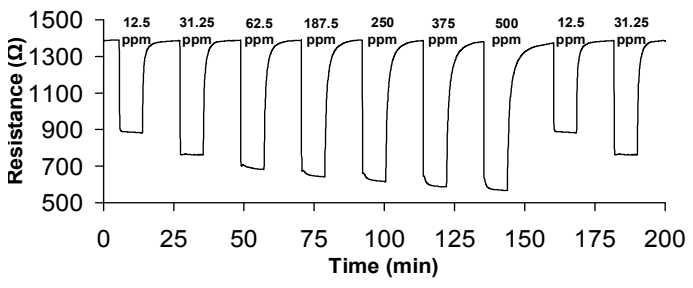

Fig. 5: Dynamic response of ZnO NRs based sensor towards different concentrations of ethanol in synthetic air at the optimum temperature of $280^{\circ} \mathrm{C}$.

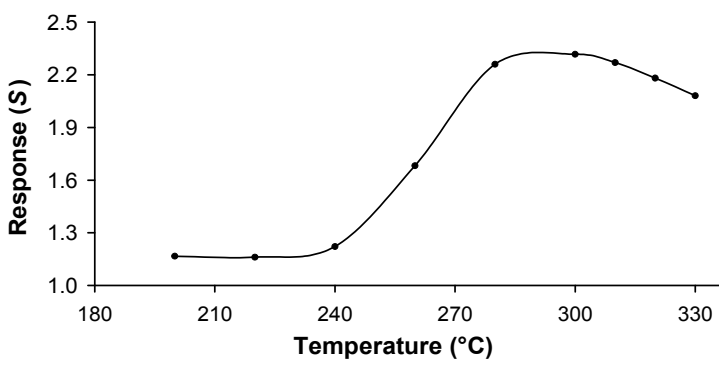

Fig. 6: Sensor response vs. operating temperature of $250 \mathrm{ppm}$ ethanol concentration in synthetic air.

The sensing mechanism is based on the reactions that occur at the sensor surface between the NRs and the ethanol molecules. When an n-type ZnO NRs is exposed to air, it is well known that the oxygen $\left(\mathrm{O}_{2}\right)$ molecules will adsorb onto the surfaces of the NRs $[13,14]$. The adsorbed oxygen molecules will form a depletion layer by capturing electrons from the NRs surface [14]. When the sensor is exposed to a reducing gas such as ethanol vapor at an elevated temperature, the vapor molecules dissociate and combine with the 
adsorbed oxygen. During this process, electrons are re-injected back into the conduction band and as a result a reduction of the depletion layer. This mechanism results in an enhancement of film conductivity which corresponds to the exposed gas concentration.

\section{Conclusions}

An ethanol vapour sensor has been fabricated based on 1D ZnO NRs thin film synthesized by a simple hydrothermal method. The fabrication of 1D ZnO NRs was achieved by predepositing a 1D $\mathrm{ZnO}$ seed layer employing FCVA technique on alumina substrates with patterned IDT. The sensor shows a repeatable and fast response towards ethanol. The optimum operating temperatures are in the range of 280 to $310{ }^{\circ} \mathrm{C}$. The measured sensor response and recovery time was about 16 and $120 \mathrm{~s}$, respectively towards $250 \mathrm{ppm}$ of ethanol at $280{ }^{\circ} \mathrm{C}$. The sensors are promising for industrial applications.

\section{References}

[1] L.F. Dong, Z.L. Cui, Z.K. Zhang, Gas sensing properties of nano-ZnO prepared by arc plasma method, Nanostructured Materials 8, 815-823 (1997); doi: 10.1016/s0965-9773(98)00005-1

[2] Z.L. Wang, Nanostructures of zinc oxide, Materials Today 7, 26-33 (2004); doi: 10.1016/S1369-7021(04)00286-X

[3] Z. Wang, X.F. Qian, J. Yin, Z.K. Zhu, Largescale fabrication of tower-like, flower-like, and tube-like $\mathrm{ZnO}$ arrays by a simple chemical solution route, Langmuir 20, 3441-3448 (2004); doi: $10.1021 / \mathrm{la0} 6098 \mathrm{n}$

[4] Z.L. Wang, Splendid one-dimensional nanostructures of zinc oxide: $A$ new nanomaterial family for nanotechnology, ACS Nano 2, 1987-1992 (2008); doi: 10.1021/nn800631r

[5] A.Z. Sadek, S. Choopun, W. Wlodarski, S.J. Ippolito, K. Kalantar-zadeh, Characterization of $\mathrm{ZnO}$ nanobelt-based gas sensor for $\mathrm{H}_{2}, \quad \mathrm{NO}_{2}$, and hydrocarbon sensing, Sensors Journal, IEEE 7, 919-924 (2007); doi: 10.1109/JSEN.2007.895963
[6] R. B.Bhooloka, Zinc oxide ceramic semiconductor gas sensor for ethanol vapour, Materials Chemistry and Physics 64, 62-65 (2000); doi: 10.1016/s0254-0584(99)00267-9

[7] K. Kohse-Höinghaus, P. Oßwald, T.A. Cool, T. Kasper, N. Hansen, F. Qi, C.K. Westbrook, P.R. Westmoreland, Biofuel combustion chemistry: From ethanol to biodiesel, Angewandte Chemie International Edition 49, 3572-3597 (2010); doi: 10.1002/anie. 200905335

[8] A.K. Agarwal, Biofuels (alcohols and biodiesel) applications as fuels for internal combustion engines, Prog. Energy Combust. Sci. 33, 233271 (2007); doi: 10.1016/j.pecs.2006.08.003

[9] A. Berna, Metal oxide sensors for electronic noses and their application to food analysis, Sensors 10, 3882-3910 (2010); doi: 10.3390/s100403882

[10] A.Z. Sadek, W. Wlodarski, Y.X. Li, W. Yu, X. Li, X. Yu, K. Kalantar-zadeh, A ZnO nanorod based layered $\mathrm{ZnO} / 64^{\circ} \mathrm{YX}$ $\mathrm{LiNbO}_{3}$ SAW hydrogen gas sensor, Thin Solid Films 515, 8705-8708 (2007); doi: 10.1016/j.tsf.2007.04.009

[11] M. Breedon, M.B. Rahmani, S.-H. Keshmiri, W. Wlodarski, K. Kalantar-zadeh, Aqueous synthesis of interconnected $\mathrm{ZnO}$ nanowires using spray pyrolysis deposited seed layers, Materials Letters 64, 291-294 (2009); doi: 10.1016/j.matlet.2009.10.065

[12] N.H. Al-Hardan, M.J. Abdullah, A. Abdul Aziz, H. Ahmad, L.Y. Low, ZnO thin films for VOC sensing applications, Vacuum 85, 101-106 (2010); doi: 10.1016/j.vacuum.2010.04.009

[13] N.F. Hamedani, A.R. Mahjoub, A.A. Khodadadi, Y. Mortazavi, Microwave assisted fast synthesis of various $\mathrm{ZnO}$ morphologies for selective detection of $\mathrm{CO}, \mathrm{CH}_{4}$ and ethanol, Sensors and Actuators B: Chemical 156, 737-742 (2011); doi: 10.1016/j.snb.2011.02.028

[14] S. Santra, P.K. Guha, S.Z. Ali, P. Hiralal, H.E. Unalan, J.A. Covington, G.A.J. Amaratunga, W.I. Milne, J.W. Gardner, F. Udrea, ZnO nanowires grown on SOI CMOS substrate for ethanol sensing, Sensors and Actuators B: Chemical 146, 559-565 (2010); doi: 10.1016/j.snb.2010.01.009 